\title{
25 Research Square \\ Psychometric Evaluation of the Taiwanese Version of the Western Ontario Rotator Cuff Index
}

\section{Kuo-Min Chu}

Taipei Veterans General Hospital

\section{Hsiao-Li Ma}

Taipei Veterans General Hospital

\section{Li-Hwa Lin}

Taipei Veterans General Hospital

\section{Hsiu-Chu Hsu}

Taipei Veterans General Hospital

Shiow-Ching Shun ( $\sim$ scshun@nycu.edu.tw)

National Yang-Ming University: National Yang Ming Chiao Tung University https://orcid.org/00000002-9883-4446

\section{Research article}

Keywords: rotator cuff tear, Western Ontario Rotator Cuff, Psychometric evaluation

Posted Date: September 17th, 2021

DOI: https://doi.org/10.21203/rs.3.rs-877923/v1

License: (c) (i) This work is licensed under a Creative Commons Attribution 4.0 International License.

Read Full License 


\section{Abstract}

Background: The Western Ontario Rotator Cuff (WORC) index is a self-report questionnaire that measures the disease-specific quality of life in patients with rotator cuff injuries. The aim of this study was to evaluate the psychometric properties of the Taiwanese version of WORC (T-WORC) in patients with rotator cuff tear (RCT) before surgery.

Methods: A cross-sectional study design was used. The study was composed of two phases: translation of the WORC into Taiwanese version of WORC, and 210 patients with rotator cuff tear before surgery completed the questionnaire twice within 2 weeks. The main outcome measures included reliability and validity. Reliability was assessed with internal consistency and test-retest. Internal consistency was assessed using the Cronbach's alpha and test-retest reliability was assessed using the intraclass correlation coefficient (ICC). Construct validity was evaluated by examining convergent, divergent, knowngroup validity, and exploratory factor analysis (EFA).

Results: The T-WORC demonstrated satisfactory reliability with the Cronbach's alpha of .94, and ICC (2 week-interval) of .79. The convergent validity showed that the T-WORC was significantly positively correlated with the disability of the arm, shoulder, and hand and numerical rating scales of pain, but negatively correlated with the Short Form-12. The divergent validity was shown by the low correlation between T-WORC and state anger scale. The known-group validity showed a significant difference between the high pain group and the low pain group. The EFA revealed 4 factors, daily activities and function, physical symptoms, emotion, and shoulder clicking and recreation, which explained $66.13 \%$ of the variance.

Conclusions: The findings of this study did not support the 5-domain structure proposed by the original version. Nevertheless, the T-WORC still demonstrated adequate psychometric properties and could be a useful instrument for assessing the RCT patients' quality of life before surgery.

\section{Introduction}

Rotator cuff tear (RCT) is a common musculoskeletal disorder and the most common condition affecting the shoulder [1-4]. Its high prevalence rate causes high direct as well as indirect costs in industrialized countries [5]. The rotator cuff of the shoulder consists of four muscle-tendon units: the supraspinatus, infraspinatus, subscapularis, and teres minor. These four muscles play an active role in maintaining the stability of the shoulder joint $[1,2,6]$. Several factors have been proposed as contributing to the development of rotator cuff lesions, including tendon hypovascularity, and tendon overload-overuse, subacromial impingement, glenohumeral instability, congenital anomalies, trauma, and tendon degeneration [1, 2]. Degenerative changes of the RCT are common in the elderly population, it tends to occur in adults over 40 years of age [7], and increases by age [1, 8]. The incidence rate of full-thickness RCT was $28 \%$ in people over 60 years old; however, rates increased up to $80 \%$ in people over 80 years old [8]. 
The RCT can cause shoulder pain, muscle weakness, activity limitation, shoulder dysfunction, partial or total inability to work, which may impair quality of life (QoL) [2]. The most chief complaints of RCT patients are shoulder pain and waking up during the night due to severe pain $[2,7,9,10]$. Poor sleep quality may lead to impaired daytime functioning such as memory impairment, attention deficits, exhaustion [11], in advanced stages, may even have a negative on daily activities [9], which may cause significant deterioration in the QoL of patients afflicted [11]. The improvement of QoL is one of the important goals of treatment for RCT patients [12]. Therefore, clinically, outcome measures should be included QoL to understand and monitor the impact of rotator cuff tear on patients, identify the optimal treatment, and assess the need for intervention [13].

Quality of life is a very broad concept, including health status, physical functioning, symptoms, psychosocial adjustment, well-being, and life satisfaction [14]. Various instruments have been developed to measure global QoL which included the index of Well-Being and the Short Form-36. The global QoL designed for use across a wide range of disease states and populations, and they are unlikely to detect small differences, or clinically important changes in the disease-specific QoL of patients, such as for the patients with RCT [15]. Disease-specific instruments of QoL are more sensitive to disease-specific changes [16]. The Western Ontario Rotator Cuff index (WORC) developed by Dr. Kirkley and colleagues is one of the most commonly used disease-specific questionnaires for the patients with RCT [15, 17-19].

The WORC is an easy assessment instrument with 21 items including five domains of physical symptoms, sports/recreation, work, lifestyle, and emotion $[15,18,20,21]$ and it has been psychometrically tested in multiple languages, including Chinese [18]. However, both the Chinese version and the original version have not been performed factorial validity by exploratory factor analysis. Factor analysis often plays a crucial role in establishing evidence for construct validity. In psychometrics, exploratory factor analysis (EFA) is used to identify a set of factors from a set of test items designed to measure certain constructs manifested as examinee attributes or traits [22]. Therefore, it is important to examine the factorial validity of T-WORC. To the best of the authors' knowledge, there are only two studies that performed factor analysis for the WORC, one in English and the other in French [20, 21]. However, their study findings by the factor analysis did not support the original version with 5 factors. The English version has been identified as three factors [20]; whereas, the French version has been identified as four factors [21].

The purpose of this study was to evaluate the psychometric properties of the Taiwanese version of the WORC in RCT patients.

\section{Methods}

\section{Design and setting}

This study used a cross-sectional study design with convenience samples and conducted from

September 2017 to February 2019. A two-phase process was used in this study to evaluate psychometric 
properties. Phase 1 was a linguistic validation. Phase 2 was a psychometric validation. Written permission was granted to the translation by one of the original authors of the WORC.

\section{Procedure for evaluating psychometric properties}

\section{Linguistic validation}

The T-WORC was translated according to the original author's recommendations [23]. Forward translation from the English version of the WORC to the T-WORC was done by two independent individuals. One translator was a doctoral student of nursing and the other translator was a physician of orthopaedics, and then two forward translators and researchers had a discussion, by exchanging and discussing, a group consensus was reached and "forward translation" was established. In order to assess conceptual equivalence with the original version. The T-WORC was translated back into English by an English teacher who is bilingual, and who never saw the original version of the questionnaire. The semantic equivalence of the original version of WORC and translated T-WORC was compared by a native English-speaking professional of nursing. Then "backward translation" was completed. Finally, an expert committee consisted of five professionals (a doctoral nursing student, a nursing teacher, a nurse practitioner, a nursing supervisor, and an attending physician) reviewed each item of T-WORC, and rated on a 4-point Likert scale of each item for meaning clarity, understanding, and wording. If any item was rated as 2 or below it was retranslated, if it was rated as three, it would be revised according to the experts' suggestions. Among the 21 items, item 9 was rated by experts as 3 in "understanding" "how much difficulty do you have with someone or something coming in contact with your affected shoulder?", the answer ranged from "no fear" to "extremely fear". According to the expert committee's suggestion and the original author's consent, we replaced "fear" with "difficult" to answer the question of item 9 of the TWORC. Then the final version of T-WORC was completed and adopted for the study.

\section{Participants}

All patients with the disease of rotator cuff tears were recruited from a teaching hospital in northern Taiwan. The inclusion criteria were: (a) aged 20 years or older; (b) the diagnosis was a rotator cuff tear and waiting for surgery; (c) able to speak Mandarin or Taiwanese language and have the reading ability at the elementary school level. The exclusion criteria were (a) the patient who had clavicle, scapula, and humeral fractures; (b) cognitive impairment; (c) and rheumatic disease.

The data were collected from inpatient and outpatient departments. In the inpatient department, while the patient admitted to the ward, the first author who then contacted them directly and explained the purpose of this research. If patients met the screening criteria and agreed to participate, they were requested to complete a written consent form and asked to fill in the questionnaires. Thirty patients were measured at two different time points for testing the test-retest reliability. Time 1 was in the outpatient department and time 2 was 2 weeks later. Patients diagnosed with RCT were referred by the physician to a well-trained research assistant and informed about the study. T2 (2-week later), the patients needed to complete the TWORC questionnaire at home, and returned the questionnaire to the researcher by mail, or brought it to 
the researcher when they were hospitalized. The 2-week interval for assessing test-retest reliability was chosen because the patients unlikely to change much during the 2 weeks while they were waiting for surgery, and it was long enough for patients to forget the previous experience of answering.

\section{Sample size}

Based on the Polit \& Beck's (2012) instruction calculated sample size, 10 participants per each item, it totally need a sample size of at least 210 [24]. A total of 218 patients met the sampling criteria, eight of whom refused to participate because of loss of interest. Finally, a total of 210 patients were recruited. The refusal rate was $3.7 \%$. The sample power was .89 with sample size of 210 , a was set at .05 and effect size was set at 2 .

\section{Measurements}

Six instruments were used in this study including demographic and disease characteristics form, the TWORC, the Quick Disabilities of the Arm, Shoulder, and Hand (QuickDASH), the Short Form-12 (SF-12), the State Anger Scale (SAS), and the Numerical Rating Scales (NRS) of pain.

\section{Participants demographic and disease characteristics}

The RCT patient's demographic and disease details included age, gender, marital status, education, employment, affected side, dominant side, and pain duration.

\section{Western Ontario Rotator Cuff index (WORC)}

The WORC was developed to measure disease-related QoL of patients who suffer from RCTs disorders [15]. It has 21 items with five domains. Each item in WORC has a possible score from 0-100-mm visual analogue scale (VAS). The maximum score of WORC is 2100 , and the minimum score is 0 , the higher the score, the worse the QoL. The total score can also be converted into a percentage score, range from $0 \%$ to $100 \%$. The total score is subtracted from 2100 and divided by $2100 \times 100$ for the \% [15]. The WORC demonstrated good internal consistency reliability (Cronbach's $a=.98$ ) [21], and test-retest reliability with Intra-class correlation coefficient (ICC) of .96 [15]. The Chinese version's Cronbach's a was .95 and the ICC was $.96[25]$.

\section{Quick Disabilities of the Arm, Shoulder, and Hand (QuickDASH)}

The 11-item QuickDASH is a shortened version of the 30-item Disabilities of the Arm, Shoulder and Hand [26]. It measures symptoms and physical function in patients with disorders of the upper extremity including total shoulder arthroplasty, rotator cuff tendinopathy, carpal tunnel syndrome, wrist/hand tendinitis. Each item scored 0-5, transforming score from 0 (no disability) to 100 (most severe disability). A higher score indicates greater disability. The QuickDASH has good internal consistency reliability $(a=$ .92) [26]. In this study, Cronbach's a was .896. 
The SF-12 is an instrument for measuring the QoL. There are 12 items, which is a subset of the SF-36 health survey and resembles the SF - 36 in the constructs and interpretation of scores. The psychometric properties were able to reproduce more than $90 \otimes$ of the variance in the physical and the mental subscales of the SF-36, and reproduced the profile of the eight dimensions of the SF-36. The SF-12 includes two main domains, the physical component summary (PCS) and the mental component summary (MCS), and eight subscales for assessing eight dimensions: physical functioning, role physical, social functioning, role- emotional, bodily pain, general health, vitality, and mental health [27]. We used the QualityMetric Health Outcomes Scoring Software 2 to calculate the PCS and the MCS scores. Scale scores were transformed into 0 (the worst) to 100 (the best). The higher the score indicates better the QoL. The SF-12 demonstrated good internal consistency reliability, Cronbach's a was .91 for the elderly population in Chinese [28]. In this study, Cronbach's a was .91.

\section{State Anger Scale (SAS)}

The SAS was developed by Chiu [29]. The questionnaire consists of 10 items. Scoring for each item ranges from 1 (not compliance with the emotional state of the moment at all) to 7 (full compliance with the emotional state of the moment). Higher scores indicate higher levels of anger. Cronbach's a was .607 [29]. In this study, Cronbach's a was .953.

\section{Numerical Rating Scales (NRS) of pain}

In this study, we wanted to know how well the T-WORC discriminates between subgroups of the study sample that differed in their pain scores. Overall shoulder pain was assessed according to an 11-point NRS. The NRS of pain was highly correlated with the VAS. It is a valid and reliable pain assessment tool. The NRS of pain scale range from 0 (no pain) to 10 (worst pain). A higher score indicates more severe pain [30].

\section{Psychometric validation}

\section{Item analysis}

Three methods were used for item analysis of 21-item of the T-WORC, including average inter-item correlations, item-scale correlations, and critical ratio.

\section{Reliability}

The reliability was assessed for internal consistency and test-retest reliability.

\section{Validity}

Construct validity was evaluated by examining convergent, divergent, known-group validity, and Exploratory Factor Analysis (EFA). 
Convergent validity refers to the degree to which two measures of constructs that theoretically should be related are, indeed related [31]. Convergent validity was examined by hypothesis testing of the relations between T-WORC and QuickDASH, SF-12, and NRS of pain. Based on literature review that we hypothesized, the T-WORC would highly positively correlate with QuickDASH and NRS of pain; T-WORC would highly negatively correlate with SF-12 $[15,19,21,25]$. Divergent validity refers to the degree to which two measures of constructs that theoretically should be unrelated are, in fact not related [31] or less related [32]. Specific disease-related QoL and anger are two different concepts. So, we hypothesized that the T-WORC would be less correlated with SAS. Known-group validity means that the instrument is administered to two or more groups that are expected to differ on the critical attribute due to known characteristics [24]. High pain scores and low pain scores of RCT patients are two different characteristics, so known-group validity was examined by comparing patients who had higher pain scores (upper 73\%) with those who had lower pain scores (lower 27\%) [33]. We hypothesized that the TWORC score were significantly different between the high pain scores group and the low pain scores group.

\section{Factorial Validity}

An EFA was performed on the 21-item T-WORC using principal component analysis with oblique rotation (because all five subscales were correlated) to determine the factor structure of all the items. Additionally, the Kaiser-Meyer-Olkin (KMO) measure of sampling adequacy and Bartlett's test of sphericity were administered to check the suitability of data for factor analysis. The number of factors extracted was determined based on an eigenvalue $>1.0$ and the scree plot. Factor loadings with an absolute value of .40 and above are included [24].

\section{Ethical consideration}

This was part of a large study. Ethical approval was obtained from the institutional review board of the hospital (2016-09-010B\#1). All patients were fully informed and their consent were obtained before the study implementation. This study has no conflict of interests.

\section{Data analysis}

All statistical analyses were conducted with the Statistical Package for the Social Sciences for Windows, version 22.0, the significance of the p-value was set at a level of .05. Descriptive statistics, including means, standard deviations, and percentages were calculated for participants' demographic and disease, the T-WORC, the QuickDASH, the SF-12, the SAS, and NRS of pain. The inter-item correlations between .30 and.70, and the corrected item-scale correlations of greater than 0.5 were considered appropriate to measure the target construct [24], and independent t-test was used for testing the critical ratio. The Cronbach's a coefficients were calculated to estimate internal consistency. Test-retest reliability was calculated by intraclass correlation cofficients (ICCs). The value for Cronbach's alpha of .75 or higher is considered acceptable for the instrument's internal consistency reliability, and ICC > .75 indicated good test-retest reliability and stability [34]. To test for convergent and divergent validity, we calculated 
Pearson correlation setween the T-WORC and the QuickDASH, the NRS of pain, the SF-12, and SAS. Known-groups validity was tested by comparing pain scores of high and low, an independent t-test was used for the analysis [33].

\section{Results}

\section{Participants demographic and disease characteristics}

A total of 210 patients with rotator cuff tear before surgery were recruited (81 males and 129 females), with a mean age of $63.2 \pm 8.21$ years. The majority of patients were $60-69$ years old $(43.3 \%)$, married (80.5\%), bachelor's degree or above (34.8\%), no employment (56.7\%), right side shoulder $(67.1 \%)$, dominant side (69.5\%), and the duration of pain less than 6 months (53.3\%) (Table 1). 
Table 1

Demographic and disease characteristics of the participants. $(\mathrm{N}=210)$

\begin{tabular}{|c|c|c|}
\hline Variable & $\mathrm{n}$ & Percentage (\%) \\
\hline \multicolumn{3}{|l|}{ Age (yr) } \\
\hline$<40$ & 2 & $(1.0)$ \\
\hline $40-49$ & 15 & $(7.1)$ \\
\hline $50-59$ & 55 & $(26.2)$ \\
\hline $60-69$ & 91 & $(43.3)$ \\
\hline$\geq 70$ & 47 & $(22.4)$ \\
\hline \multicolumn{3}{|l|}{ Gender } \\
\hline Male & 81 & $(38.6)$ \\
\hline Female & 129 & $(61.4)$ \\
\hline \multicolumn{3}{|l|}{ Marital status } \\
\hline Married & 169 & $(80.5)$ \\
\hline Unmarried & 6 & $(2.9)$ \\
\hline Divorce & 15 & $(7.1)$ \\
\hline Widowed & 20 & (9.5) \\
\hline \multicolumn{3}{|l|}{ Education } \\
\hline Primary school degree or below & 49 & $(23.3)$ \\
\hline Junior middle degree & 45 & $(21.4)$ \\
\hline High school degree & 43 & $(20.5)$ \\
\hline Bachelor's degree or above & 73 & $(34.8)$ \\
\hline \multicolumn{3}{|l|}{ Employment } \\
\hline No & 119 & $(56.7)$ \\
\hline Yes & 91 & $(43.3)$ \\
\hline \multicolumn{3}{|l|}{ Affected side } \\
\hline Left side shoulder & 69 & $(32.9)$ \\
\hline Right side shoulder & 141 & $(67.1)$ \\
\hline \multicolumn{3}{|l|}{ Dominant side } \\
\hline No & 64 & $(30.5)$ \\
\hline
\end{tabular}




\begin{tabular}{|lcc|} 
Yes & 146 & $(69.5)$ \\
Pain duration & & \\
$<6$ months & 1 & $(0.5)$ \\
$6-12$ months & 112 & $(53.3)$ \\
$>1$ year & 35 & $(16.7)$ \\
\hline
\end{tabular}

\section{Psychometric properties of the T-WORC}

\section{Item analysis}

The item analysis showed in Table 2. The average inter-item correlations of T-WORC were greater than .3, the corrected item-scale correlations of T-WORC were greater than .5, and the critical ratio values of 21 items of T-WORC were significant. All 21 items of the T-WORC showed good item characteristics and suitability for factor analysis. 
Table 2

Item analysis for exploratory factor analysis. $(\mathrm{N}=210)$

Item
Average

inter-item

correlations
Item-scale Critical correlations ratio

(corrected)

.518

.584

.645

.690

.447

.346

.352

6. How much discomfort do you experience in the muscles of your neck because of your shoulder?

7. How much has your shoulder affected your fitness level?

8. How much has your shoulder affected your ability to throw hard or far?

9. How much difficulty do you have with someone or something coming in contact with your affected shoulder?

10. How much difficulty do you experience doing push-ups or other strenuous shoulder exercises because of your shoulder?

11. How much difficulty do you experience in daily activities about the house or yard?

12. How much difficulty do you experience working above your head?

13. How much do you use your uninvolved arm to compensate for your injured one?

14. How much difficulty do you experience lifting heavy objects at or below shoulder level?

15. How much difficulty do you have sleeping because of your shoulder?

16. How much difficulty have you experienced with styling your hair because of your shoulder?

17. How much difficulty do you have "roughhousing or horsing around" with family or friends?
.483

.446

.465

.447

538

.456

.659

$.000^{* *}$

419

.606

$.000^{\star \star}$

483

.702

$.000^{\star \star}$

.422

606

$.000^{\star \star}$

.467

.679

$.000^{\star \star}$

.504

.734

$.000^{\star \star}$ 


\begin{tabular}{|llll|}
\hline Item & $\begin{array}{l}\text { Average } \\
\text { inter-item } \\
\text { correlations }\end{array}$ & $\begin{array}{l}\text { Item-scale } \\
\text { correlations } \\
\text { (corrected) }\end{array}$ & $\begin{array}{l}\text { Critical } \\
\text { ratio }\end{array}$ \\
\hline $\begin{array}{l}\text { 18. How much difficulty do you have dressing or undressing? } \\
\text { 19. How much frustration do you feel because of your } \\
\text { shoulder? }\end{array}$ & .528 & .772 & $.000^{\star \star}$ \\
\hline $\begin{array}{l}\text { 20. How "down in the dumps" or depressed do you feel } \\
\text { because of your shoulder? }\end{array}$ & .462 & .675 & $.000^{* \star}$ \\
\hline $\begin{array}{l}\text { 21. How worried or concerned are you about the effect of } \\
\text { your shoulder on your occupation? }\end{array}$ & .470 & .644 & $.000^{\star \star}$ \\
\hline$* p<.05, * * p<.01$ & & & $.000^{* \star}$ \\
\hline
\end{tabular}

\section{Reliability}

The Cronbach's alpha coefficient for the WORC was .94, for the subscales range from .79 to .88, and ICC for the WORC was .79. Both Cronbach's alpha coefficient and ICC are higher than .75, which demonstrated high internal consistency and test-retest reliability of the T-WORC. In the subscale, ICC for the emotion factor was .51 (Table 3).

Table 3

Internal consistency reliability and test-retest reliability for the WORC. $(\mathrm{N}=210)$

\begin{tabular}{|lllll|}
\hline Variable & Mean & SD & Cronbach's alpha & Intra-class correlation \\
\hline Total scale & 1245.97 & 420.97 & .94 & .79 \\
\hline Physical symptoms & 298.79 & 119.53 & .80 & .63 \\
\hline Sports/recreation & 257.28 & 88.15 & .79 & .77 \\
\hline Work & 251.30 & 95.67 & .81 & .61 \\
\hline Lifestyle & 256.12 & 96.31 & .83 & .85 \\
\hline Emotions & 182.49 & 83.57 & .88 & .51 \\
\hline Abbreviations: SD Standard Deviation & & \\
\hline
\end{tabular}

\section{Convergent validity and divergent validity}

A high positive correlation between T-WORC and QuickDASH $(r=.834, p=.000)$, and a high positive correlation between T-WORC and NRS of pain $(r=.745, p=.000)$. A negative correlation between T-WORC and SF-12 $(r=-.702, p=.000)$. The results also showed that the correlation between the T-WORC and 
SAS was low $(r=.286, p=.000)$. These results supported that the T-WORC has a good convergent and divergent validity.

\section{Known-group validity}

The independent $t$-test showed a significant difference $(t=-12.690, p=.000)$ in the mean score of TWORC between the high pain score group $(M=1542.81, S D=263.819)$ and the low pain score group $(M=$ $797.38, \mathrm{SD}=374.906)$. The T-WORC was able to discriminate between patients with higher pain scores and those with lower pains score.

\section{Factorial Validity}

An EFA was conducted to test whether the 5 factors proposed by the original version. The EFA demonstrated that the data were appropriate for factoring: KMO value of T-WORC was .94, which indicated an acceptable level of sampling adequacy. Bartlett's test of sphericity was highly significant $(\chi 2$ $=2719.390, p \otimes .000$ ), which indicated that these variables were adequately correlated for a factor analysis. The analysis on the T-WORC revealed 4 factors with an eigenvalue greater than 1 , which explained $66.13 \%$ of the variance (Table 4). The scree plot analysis also suggested the presence of four factors included daily activities and function (11 items), physical symptoms (4 items), emotion (3 items), and shoulder clicking and recreation (3 items). 
Table 4

Factor loadings for exploratory factor analysis with oblique rotation of the WORC. $(N=210)$

\begin{tabular}{|c|c|c|c|c|c|c|}
\hline \multirow{2}{*}{$\begin{array}{l}N \\
0\end{array}$} & \multirow[t]{2}{*}{ Item } & \multirow{2}{*}{$\begin{array}{l}\text { Mean } \\
\pm \text { SD }\end{array}$} & Factor 1 & Factor 2 & Factor 3 & Factor 4 \\
\hline & & & $\begin{array}{l}\text { Daily } \\
\text { activities } \\
\text { and } \\
\text { function }\end{array}$ & $\begin{array}{l}\text { Physical } \\
\text { symptoms }\end{array}$ & Emotion & $\begin{array}{l}\text { Shoulder } \\
\text { clicking } \\
\text { and } \\
\text { recreation }\end{array}$ \\
\hline 12 & $\begin{array}{l}\text { How much difficulty do you } \\
\text { experience working above your } \\
\text { head? }\end{array}$ & $\begin{array}{l}69.68 \\
\pm \\
29.94\end{array}$ & .857 & -.096 & .055 & .052 \\
\hline 18 & $\begin{array}{l}\text { How much difficulty do you have } \\
\text { dressing or undressing? }\end{array}$ & $\begin{array}{l}65.29 \\
\pm \\
27.12\end{array}$ & .772 & -.072 & -.171 & .044 \\
\hline 8. & $\begin{array}{l}\text { How much has your shoulder } \\
\text { affected your ability to throw hard } \\
\text { or far? }\end{array}$ & $\begin{array}{l}72.63 \\
\pm \\
26.80\end{array}$ & .771 & .142 & .008 & -.201 \\
\hline 3 & $\begin{array}{l}\text { How much weakness do you } \\
\text { experience in your shoulder? }\end{array}$ & $\begin{array}{l}51.59 \\
\pm \\
28.53\end{array}$ & .745 & .119 & .183 & .164 \\
\hline 16 & $\begin{array}{l}\text { How much difficulty have you } \\
\text { experienced with styling your hair } \\
\text { because of your shoulder? }\end{array}$ & $\begin{array}{l}60.05 \\
\pm \\
30.87\end{array}$ & .705 & -.179 & -.121 & .210 \\
\hline 10 & $\begin{array}{l}\text { How much difficulty do you } \\
\text { experience doing push-ups or } \\
\text { other strenuous shoulder exercises } \\
\text { because of your shoulder? }\end{array}$ & $\begin{array}{l}81.91 \\
\pm \\
25.67\end{array}$ & .705 & .265 & -.083 & -.371 \\
\hline 17 & $\begin{array}{l}\text { How much difficulty do you have } \\
\text { "roughhousing or horsing around" } \\
\text { with family or friends? }\end{array}$ & $\begin{array}{l}65.75 \\
\pm \\
30.62\end{array}$ & .698 & -.076 & -.269 & -.035 \\
\hline 4. & $\begin{array}{l}\text { How much stiffness or lack of } \\
\text { range of motion do you experience } \\
\text { in your shoulder? }\end{array}$ & $\begin{array}{l}55.92 \\
\pm \\
26.01\end{array}$ & .669 & .276 & .092 & .050 \\
\hline 11 & $\begin{array}{l}\text { How much difficulty do you } \\
\text { experience in daily activities about } \\
\text { the house or yard? }\end{array}$ & $\begin{array}{l}59.20 \\
\pm \\
27.14\end{array}$ & .565 & .146 & -.177 & .178 \\
\hline 13 & $\begin{array}{l}\text { How much do you use your } \\
\text { uninvolved arm to compensate for } \\
\text { your injured one? }\end{array}$ & $\begin{array}{l}55.58 \\
\pm \\
32.92\end{array}$ & .533 & -.103 & -.191 & .174 \\
\hline 14 & $\begin{array}{l}\text { How much difficulty do you } \\
\text { experience lifting heavy objects at } \\
\text { or below shoulder level? }\end{array}$ & $\begin{array}{l}66.84 \\
\pm \\
29.57\end{array}$ & .507 & .127 & -.281 & -.020 \\
\hline 1 & $\begin{array}{l}\text { How much sharp pain do you } \\
\text { experience in your shoulder? }\end{array}$ & $\begin{array}{l}59.23 \\
\pm \\
27.74\end{array}$ & .085 & .801 & .008 & .012 \\
\hline
\end{tabular}




\begin{tabular}{|c|c|c|c|c|c|c|}
\hline \multirow{2}{*}{$\begin{array}{l}\mathbf{N} \\
\mathbf{O}\end{array}$} & \multirow[t]{2}{*}{ Item } & \multirow{2}{*}{$\begin{array}{l}\text { Mean } \\
\pm \text { SD }\end{array}$} & \multirow{2}{*}{$\begin{array}{l}\text { Factor } 1 \\
\text { Daily } \\
\text { activities } \\
\text { and } \\
\text { function }\end{array}$} & \multirow{2}{*}{$\begin{array}{l}\text { Factor } 2 \\
\text { Physical } \\
\text { symptoms }\end{array}$} & \multirow{2}{*}{$\begin{array}{l}\text { Factor } 3 \\
\text { Emotion }\end{array}$} & \multirow{2}{*}{$\begin{array}{l}\text { Factor } 4 \\
\text { Shoulder } \\
\text { clicking } \\
\text { and } \\
\text { recreation }\end{array}$} \\
\hline & & & & & & \\
\hline 2 & $\begin{array}{l}\text { How much constant, nagging pain } \\
\text { do you experience in your } \\
\text { shoulder? }\end{array}$ & $\begin{array}{l}53.65 \\
\pm \\
24.55\end{array}$ & .028 & .715 & -.142 & .122 \\
\hline 15 & $\begin{array}{l}\text { How much difficulty do you have } \\
\text { sleeping because of your } \\
\text { shoulder? }\end{array}$ & $\begin{array}{l}65.04 \\
\pm \\
29.58\end{array}$ & .004 & .591 & -.367 & .018 \\
\hline 6 & $\begin{array}{l}\text { How much discomfort do you } \\
\text { experience in the muscles of your } \\
\text { neck because of your shoulder? }\end{array}$ & $\begin{array}{l}48.21 \\
\pm \\
29.64\end{array}$ & .022 & .488 & -.006 & .472 \\
\hline 20 & $\begin{array}{l}\text { How "down in the dumps" or } \\
\text { depressed do you feel because of } \\
\text { your shoulder? }\end{array}$ & $\begin{array}{l}53.03 \\
\pm \\
33.09\end{array}$ & -.046 & .067 & -.876 & .057 \\
\hline 19 & $\begin{array}{l}\text { How much frustration do you feel } \\
\text { because of your shoulder? }\end{array}$ & $\begin{array}{l}61.99 \\
\pm \\
30.01\end{array}$ & .034 & .154 & -.851 & -.111 \\
\hline 21 & $\begin{array}{l}\text { How worried or concerned are you } \\
\text { about the effect of your shoulder } \\
\text { on your occupation? }\end{array}$ & $\begin{array}{l}67.47 \\
\pm \\
29.96\end{array}$ & .157 & -.034 & -.742 & .093 \\
\hline 5 & $\begin{array}{l}\text { How much are you bothered by } \\
\text { clicking, grinding or crunching in } \\
\text { your shoulder? }\end{array}$ & $\begin{array}{l}30.19 \\
\pm \\
31.27\end{array}$ & .070 & .191 & -.035 & .697 \\
\hline 7. & $\begin{array}{l}\text { How much has your shoulder } \\
\text { affected your fitness level? }\end{array}$ & $\begin{array}{l}51.08 \\
\pm \\
28.61\end{array}$ & .357 & .153 & -.159 & .428 \\
\hline 9. & $\begin{array}{l}\text { How much difficulty do you have } \\
\text { with someone or something } \\
\text { coming in contact with your } \\
\text { affected shoulder? }\end{array}$ & $\begin{array}{l}51.65 \\
\pm \\
31.61\end{array}$ & .317 & -.015 & -.321 & .411 \\
\hline \multicolumn{7}{|c|}{$\begin{array}{l}\text { Note: A principal component analysis with oblique rotation and factor loadings greater than } 0.4 \text { on } 21 \\
\text { items that comprise the T-WORC component of the questionnaire. This analysis demonstrated four } \\
\text { factors with eigenvalues }>1.0 \text {, which explain } 66.13 \% \text { of the variance. }\end{array}$} \\
\hline $\mathrm{Fa}$ & loadings greater than 0.4 in abso & ralue & bold. & & & \\
\hline
\end{tabular}

\section{Discussion}

This study demonstrated that the T-WORC had satisfactory reliability and acceptable validity for assessing the QoL of patients with RCT before surgery. The results of the study supported our hypothesis that the known-group validity showed that the QoL of patients with high pain scores was significantly 
lower than those with low pain scores. Based on our study finding that the EFA revealed 4 factors (daily activities and function, physical symptoms, emotion, and shoulder clicking and recreation), it does not support the 5-domain structure proposed by the original version of the WORC.

In the process of factor analysis, we found that the sixth item (How much discomfort do you experience in the muscles of your neck because of your shoulder?) showed cross-loading in the factor of "physical symptoms" with factor loading .488 and "shoulder clicking and recreation" with factor loading .472 . However, since the discomfort of neck muscles was one of the important symptoms affecting the QoL of RCT patients $[7,9,10]$, besides, the loading score of "physical symptoms" was higher than another factor, therefore, we agreed to retain the item 6 into the factor of "physical symptoms". Finally, 4 factors have been identify to be inconsistent with the results of the original version of the WORC with 5 factors [15] and only the emotion factor had the same items with the original version. The reason for the inconsistence may be that five domains of the original version were derived from a literature review, expert advice, and patients [15]. The factorial validity has not been examined by factor analysis.

Furthermore, our 4-factor structure also differed from the Wessel et al. (2005) and St-Pierre et al. (2015) which were also conducted EFA to explore the factorial validity of the WORC. Wessel et al. (2005) extracted three factors (emotions \& symptoms, disability-strength activities, and disability-daily activities) of the WORC [20]; whereas, St-Pierre et al (2015) extracted four factors with daily activities and function, pain and emotions, daily life activities, and shoulder clicking and neck pain [21].There were two possible reasons for explaining such inconsistencies. First, differences in the populations' diagnoses may be likely to affect the results. Compared with the previous two studies, the diagnosis of patients in this study was more homogeneous. In this study, all patients were diagnosed as RCT waiting for surgery, and the diagnosis of patients in the previous two studies included rotator cuff pathology, superior labral anterior and posterior (SLAP) lesions before arthroscopic acromioplasty or tendinopathy, and rotator cuff tears post-operative patients $[20,21]$. The patients with SLAP tear may complain of deep-seated shoulder pain with overhead activities [7], the patients with RCT, the most common complaint is increasing night-time pain and disturbed sleep [9]. Different major related symptoms may influence different domains of their QoL.

The second reason may be caused by gender differences. In this study, the ratio of males to females was $38.6 \%$ vs $61.4 \%$, but in the study of Wessel et al. was $60 \%$ vs $40 \%$, respectively. There were differences in overall symptom perception between males and females [35]. Women generally tend to report worse QoL and self-reported health than men [36]. Our results showed that there were significant differences between male and female in lifestyle domains $(t=-3.919, p=.000)$ and emotion domains $(t=-3.267, p$ $=.000$ ), which were consistent with the previous findings that women undergoing rotator cuff surgery had a higher level of difficulty in the lifestyle domain and emotional domain [35].

In addition, this study found that in the subscale, the ICC for the emotion factor was .51. The data collection of test-retest in this study conducted at two time points, T1 was collected in the outpatient department 14 days before surgery, and T2 was collected on the day before surgery. The mean of 
emotional factors at T2 was $146.03 \pm 78.68$, which was higher than T1 $(132.87 \pm 88.48)$. As time gets closer to surgery, the patients may experience emotional responses.

\section{Implications for practice}

The WORC is a valid and reliable, clear, and ease-of-use implementation instrument for assessing the RCT patient's QoL. The instrument can assist healthcare professionals in understanding the severity of patients' symptoms affecting the QoL and the ability to perform activities of daily living. The more accurately understand the impact of RCT on QoL, the more accurate intervention can be provided to the patient. The QoL information not only provides patients as a reference for treatment decisions but also can be used as an evaluation of treatment effectiveness. Therefore, in the future studies, T-WORC can be used to compare QoL pre-surgery with post-surgery to understand the effect of surgical treatment.

\section{Limitation}

This study has some limitations that should be noted. First, this study was a cross-sectional study design. The participants were convenience-sampling recruited from the orthopaedic inpatient and outpatient departments of a teaching hospital in northern Taiwan; therefore, causal inferences from this study were limited. Second, due to the insufficient sample size, we did not conduct a confirmatory factor analysis (CFA). Our study was based on EFA analysis, and four factors were derived, in order to assess the factorial structure found in EFA, it is suggested that a CFA should be performed in the future. Finally, the responsiveness of the T-WORC was not tested in this study. In addition to the responsiveness of scale statistics, the responsiveness of patients should also be discussed with objective measurement. Therefore, the responsiveness of subjective and objective data should be examined in the future.

\section{Conclusion}

In conclusion, the T-WORC with 4 factors demonstrated adequate psychometric properties. Although our study finding did not support the 5-domain structure proposed by the original version, it is still a useful instrument for assessing the RCT patients' QoL before surgery.

\section{Abbreviations}

WORC: Western Ontario Rotator Cuff; T-WORC: Taiwanese version of WORC; RCT: Rotator cuff tear; QuickDASH: Quick disabilities of the arm, shoulder, and hand; SF-12: Short Form-12; PCS: Physical component summary; MCS: Mental component summary; SAS: state anger scale; NRS: numerical rating scales; NRS: numerical rating scale; VAS: visual analogue scale; ICC: intraclass correlation coefficient; EFA: exploratory factor analysis; QoL: quality of life.

\section{Declarations}

Acknowledgments 
The authors gratefully acknowledge the assistance of the patients who participated in this study and a supporting grant from the Taipei Veterans General Hospital (V106- 017).

\section{Authors' contributions}

K-MC was the first author responsible for the study design and manuscript writing. H-LM participated in the design of the study. $\mathrm{H}-\mathrm{CH}$ collected data. $\mathrm{K}-\mathrm{MC}$ and $\mathrm{L}-\mathrm{HL}$ performed the statistical analysis and interpreted data. S-CS was the corresponding author responsible for reviewing and editing the manuscript. All authors read, reviewed, and approved the final manuscript.

\section{Funding}

This study did not receive specific grant from any funding agency in the public, commercial, or not-forprofit sectors.

\section{Availability of data and materials}

The data that support the findings of this study are available from the corresponding author on reasonable request.

\section{Ethics approval and consent to participate}

Ethical approval was obtained from the institutional review board of the Taipei Veterans General Hospital (IRB no. 2016-09-010B\#1) and written informed consents were obtained from all participants.

\section{Consent for publication}

Not applicable

\section{Competing interests}

The authors declare that they have no competing interests.

\section{References}

1. Skirven TM, Osterman AL, Fedorczyk J, Amadio PC, Felder S, Shin EK. Rehabilitation of the hand and upper extremity. 7th ed. Philadelphia: Elsevier Health Sciences; 2020.

2. Gumina S. Rotator cuff tear: pathogenesis, evaluation and treatment. Switzerland: Springer International Publishing; 2016.

3. Rodríguez LR, Izquierdo TG, Martín DP. Adaptation and transcultural translation of the rotator cuff quality of life questionnaire into Spanish. J Shoulder Elbow Surg. 2020;29(2):355-62. https://doi.org/10.1016/j.jse.2019.07.015

4. Wiertsema SH, Rietberg MB, Hekman KM, Schothorst M, Steultjens MP, Dekker J. Reproducibility of the Dutch version of the Western Ontario Rotator Cuff index. J Shoulder Elbow Surg. 2013;22(2):165- 
70. https://doi.org/10.1016/j.jse.2012.03.014

5. Maffulli N, Furia JP. Rotator cuff disorders: basic science and clinical medicine. London: JP Medical Limited; 2012.

6. Vosloo M, Keough N, De Beer MA. The clinical anatomy of the insertion of the rotator cuff tendons. Eur J Orthop Surg Traumatol. 2017;27(3):359-66. https://doi.org/10.1007/s00590-017-1922-z

7. Frontera WR, Silver JK, Rizzo TD. Essentials of physical medicine and rehabilitation. 4th ed. Philadelphia: Elsevier Health Sciences; 2018.

8. Park JG, Cho NS, Song JH, Baek JH, Jeong HY, Rhee YG. Rotator cuff repair in patients over 75 years of age: clinical outcome and repair integrity. Clin Orthop Surg. 2016;8(4):420-7. https://doi.org/10.4055/cios.2016.8.4.420

9. Serbest S, Tiftikçi U, Askin A, Yaman F, Alpua M. Preoperative and post-operative sleep quality evaluation in rotator cuff tear patients. Knee Surg Sports Traumatol Arthrosc. 2017;25(7):2109-13. https://doi.org/10.1007/s00167-016-4228-5

10. Ansok CB, Khalil LS, Muh S. Objective assessment of sleep quality in patients with rotator cuff tears. Orthop Traumatol Surg Res. 2020;106(1):61-6. https://doi.org/10.1016/j.otsr.2019.09.033

11. Sariarslan HA, Gulhan YB, Unalan D, Basturk M, Delibas S. The relationship of sleep problems to life quality and depression. Neurosciences (Riyadh). 2015;20(3):236-42.

https://doi.org/10.17712/nsj.2015.3.20150157

12. Çınar-Medeni Ö, Ozengin N, Baltaci G, Duzgun I. Turkish version of the rotator cuff quality of life questionnaire in rotator cuff-impaired patients. Knee Surg Sports Traumatol Arthrosc. 2015;23(2):591-5. https://doi.org/10.1007/s00167-014-3290-0

13. Magee DJ, Zachazewski JE, Quillen WS, Manske RC. Pathology and intervention in musculoskeletal rehabilitation. 2nd ed. Maryland Heights: Elsevier Health Sciences; 2015.

14. Barofsky I. Can quality or quality-of-life be defined? Qual life Res. 2012;21(4):625-31. https:// doi.org/10.1007/s11136-011-9961-0

15. Kirkley A, Alvarez C, Griffin S. The development and evaluation of a disease-specific quality-of-life questionnaire for disorders of the rotator cuff: The Western Ontario Rotator Cuff index. Clin J Sport Med. 2003;13(2):84-92. https://doi.org/10.1097/00042752-200303000-00004

16. Kolk A, Wolterbeek N, Auw Yang KG, Zijl JAC, Wessel RN. Predictors of disease-specific quality of life after arthroscopic rotator cuff repair. Int Orthop. 2016;40(2):323-9. https://doi.org/10.1007/s00264015-2996-z

17. St-Pierre C, Desmeules F, Dionne CE, Frémont P, MacDermid JC, Roy J-S. Psychometric properties of self-reported questionnaires for the evaluation of symptoms and functional limitations in individuals with rotator cuff disorders: a systematic review. Disabil Rehabil. 2016;38(2):103-22. https://doi.org/10.3109/09638288.2015.1027004

18. Furtado R, MacDermid JC, Nazari G, Bryant DM, Faber KJ, Athwal GS. Cross-cultural adaptions and measurement properties of the WORC (Western Ontario rotator cuff index): a systematic review. Health Qual Life Outcomes. 2020;18(1):17. https://doi.org/10.1186/s12955-020-1276-9 
19. Huang H, Grant JA, Miller BS, Mirza FM, Gagnier JJ. A Systematic review of the psychometric properties of patient-reported outcome instruments for use in patients with rotator cuff disease. Am J Sports Med. 2015;43(10):2572-82. https://doi.org/10.1177/0363546514565096

20. Wessel J, Razmjou H, Mewa Y, Holtby R. The factor validity of the Western Ontario Rotator Cuff index. BMC Musculoskelet disord. 2005;6:22. https://1186/1471-2474-6-22

21. St-Pierre C, Dionne CE, Desmeules F, Roy J-S. Reliability, validity, and responsiveness of a Canadian French adaptation of the Western Ontario Rotator Cuff (WORC) index. J Hand Ther. 2015;28(3):292-8; quiz 299. https://doi.org/10.1016/j.jht.2015.02.001

22. Price LR. Psychometric methods: theory into practice. New York: Guilford Publications; 2016.

23. Tyupa S, Wild D. Translating clinical trial outcomes measures: an overview. Italy: SEEd; 2016.

24. Polit DF, Beck CT. Nursing research: generating and assessing evidence for nursing practice. 9th ed. Philadelphia: Wolters Kluwer Health/Lippincott Williams \& Wilkins; 2012.

25. Wang W, Xie Q-Y, Jia Z-Y, Cui L, Liu D, Wang C-R, et al. Cross-cultural translation of the Western Ontario Cuff index in Chinese and its validation in patients with rotator cuff disorders. BMC Musculoskelet disord. 2017;18(1):178. https://doi.org/10.1186/s12891-017-1536-y

26. Beaton DE, Wright JG, Katz JN, Upper Extremity Collaborative G. Development of the QuickDASH: comparison of three item-reduction approaches. J Bone Joint Surg Am. 2005;87(5):1038-46. https:// doi.org/10.2106/JBJS.D.02060

27. Ware J, Kosinski M, Keller SD. A 12-item Short-Form health survey: construction of scales and preliminary tests of reliability and validity. Med care. 1996;34(3):220-33. https:// doi.org/10.1097/00005650-199603000-00003

28. Shou J, Ren L, Wang H, Yan F, Cao X, Wang H, et al. Reliability and validity of 12-item Short-Form health survey (SF-12) for the health status of Chinese community elderly population in Xujiahui district of Shanghai. Aging Clin Exp Res. 2016;28(2):339-46. https:// doi.org/10.1007/s40520-0150401-9

29. Chiu H, Y. The Influence of anger on fear reduction. [Master's thesis]. Taipei, Taiwan: Fu Hsing Kang College, National Defense University; 2012.

30. Breivik EK, Björnsson GA, Skovlund E. A comparison of pain rating scales by sampling from clinical trial data. Clin J Pain. 2000;16(1):22-8. https://doi.org/10.1097/00002508-200003000-00005

31. Chiappelli F. Fundamentals of evidence-based health care and translational science. New York: Springer; 2014.

32. Thielsch MT, Wetterkamp M, Boertz P, Gosheger G, Schulte TL. Reliability and validity of the Spinal Appearance Questionnaire (SAQ) and the Trunk Appearance Perception Scale (TAPS). J Orthop Surg Res. 2018;13(1):274. https://dx.doi.org/10.1186/s13018-018-0980-1

33. Wu ML. SPSS operation and application: The practice of quantitative analysis of questionnaire data. Taipei: Wu-Nan Book Inc; 2009. 
34. Brinkerhoff BN. Ergonomics: design, integration and implementation. New York: Nova Science Publishers; 2009.

35. Razmjou H, Holtby R, Myhr T. Gender differences in quality of life and extent of rotator cuff pathology. Arthroscopy. 2006;22(1):57-62. https://doi.org/10.1016/j.arthro.2005.10.014

36. Coley SL, Carlos FMdL, Ward EC, Barnes LL, Skarupski KA, Jacobs EA. Perceived discrimination and health-related quality-of-life: gender differences among older African Americans. Qual Life Res. 2017;26(12):3449-58. https:// doi.org/10.1007/s11136-017-1663-9

\section{Supplementary Files}

This is a list of supplementary files associated with this preprint. Click to download.

- 1.permissionofWORC.pdf

- 2.WORCinvoce.pdf

- 3.permissionofDASH.pdf.pdf

- 4.SF12invoce.pdf 